\title{
RESENHA: VELHO É LINDO!
}

Débora Pires Teixeira

GOLDENBERG, Mirian (ORG.). Velho É LINDO! RIO dE JANEIRO: CIVILIZAÇÃO BRASILEIRA, 2016. 280 P.

O livro Velho é lindo!, lançado em 2016 pela editora Civilização Brasileira, é uma coletânea de artigos organizada pela antropóloga Mirian Goldenberg, professora e pesquisadora do Programa de Pós-Graduação em Ciências Sociais da Universidade Federal do Rio de Janeiro (UFRJ), nome inescapável nos estudos sobre corpo, sexualidade, conjugalidade, infidelidade, felicidade e envelhecimento, sobretudo no que diz respeito ao cenário nacional e, em especial, ao carioca.

Dando sequência à temática desenvolvida no livro A bela velhice (2013), de autoria de Mirian Goldenberg, Velho é lindo! reúne nove artigos de pesquisadores da França e do Brasil e tem como proposta:

[...] trazer reflexões importantes e originais para pensar o envelhecimento de maneira mais positiva, plena e feliz. Em diferentes perspectivas com base no

1 Graduada em Economia Doméstica pela Universidade Federal de Viçosa. Doutoranda do Programa de Pós-Graduação em Economia Doméstica da Universidade Federal de Viçosa. Professora Adjunta da Universidade Federal Rural do Rio de Janeiro, vinculada ao Departamento de Economia Doméstica e Hotelaria. E-mail: deborapires@ufrrj.br. 
O primeiro capítulo, teórico, é de autoria de Vicent Caradec sociólogo francês, professor de Sociologia da Universidade de Lille (França) e referência nos estudos sobre envelhecimento. O segundo capítulo, de Diana Felgueiras das Neves, é fruto de sua pesquisa de mestrado vinculada ao Programa de Pós-Graduação em Direito e Sociologia da Universidade Federal Fluminense (UFF), coorientado por Mirian Goldenberg. Os demais capítulos são desdobramentos de dissertações e teses produzidas no Programa de Pós-Graduação em Sociologia e Antropologia do Instituto de Filosofia e Ciências Sociais (IFCS) da Universidade Federal do Rio de Janeiro (UFRJ). Parte deles faz parte da pesquisa "Corpo, envelhecimento e felicidade" coordenada por Mirian Goldenberg.

No capítulo de Vicent Caradec, intitulado "Da terceira idade à idade avançada: a conquista da velhice", o autor destaca as alterações nas representações da velhice pós conquista da aposentadoria, no território francês. Para o autor, a associação da velhice à senescência, presente nos discursos desde o final século XIX, tem sido contrastada com as profundas transformações atuais que estão sendo presenciadas nos países do Norte, com destaque para a França. Dois momentos se fazem importantes para a compreensão da "conquista da velhice": o primeiro, nas décadas de 1970 e 1980, com o surgimento da terceira idade e que envolveu os primeiros anos de aposentadoria e o segundo, em curso, centra-se na "conquista da idade avançada".

Vicent Caradec atribui a conquista da terceira idade às condições econômicas, demográficas e às mudanças culturais em relação à velhice. Ao mesmo tempo, o movimento de terceira idade, que dissociou aposentadoria de velhice, fez surgir a "idade avançada", ou seja, um segundo momento da aposentadoria ligada ao tempo de senescência e ao declínio. No entanto, hoje, esse período da "idade avançada" é que está sendo revisto. Há vários fenômenos que contribuem para essa mudança, dentre eles estão: o aumento da longevidade; um modelo cultural mais positivo da idade avançada e o que autor chamou de "teste da idade avançada". É nesse novo contexto que os muito idosos têm inventado, de forma individual, maneiras de viver a etapa da idade avançada, já que as pessoas mais velhas estão desigualmente sujeitas a esse "teste", dispondo também de recursos diferenciados para superá-lo (CARADEC, 2016).

O segundo capítulo, "Mulheres de cabelos brancos: reflexões sobre o desvio e padrões de feminilidade", de autoria da pesquisadora Denise Felgueiras das 
Neves, apresenta considerações sobre a interseccionalidade gênero e geração, buscando compreender a manutenção de cabelos brancos como um signo distintivo de envelhecimento em um universo que desvaloriza tais sinais. Para tanto, a autora investigou dezessete mulheres cariocas de 29 a 58 anos que deixam seus cabelos grisalhos visíveis.

Em um país no qual a manutenção do corpo jovem representa a preocupação central das mulheres, os cabelos brancos podem significar uma estética desviante. No entanto, Neves (2006) não afirma que as pesquisadas representam modelos plenos de luta contra os padrões hegemônicos de beleza, pois apesar de estarem satisfeitas com sua aparência e, em alguns casos, perceberem o cabelo branco como um capital no mercado profissional, afetivo e sexual, apresentam contradições em seus discursos relatando a utilização de outros recursos antienvelhecimento. Para Neves (2016), tais contradições, entretanto, não retiram o caráter desviante das entrevistadas, já que não é possível esperar de alguém o completo desvio, "a grande recusa" aos padrões estéticos vigentes, o que esconderia a complexidade dos processos de performance da feminilidade.

O capítulo 3, de Fernanda dos Reis Rougemont, intitulado "A longevidade da juventude", refere-se à discussão dos resultados de uma pesquisa dividida em duas etapas: de campo e documental. A primeira foi realizada com aplicação de 1617 questionários a homens e mulheres da cidade do Rio de Janeiro, com idades entre 18 a 97 anos, objetivando compreender a concepção dos pesquisados a respeito do ciclo de vida, de forma mais específica, sobre a velhice. Na segunda etapa, os dados obtidos com a pesquisa de campo foram comparados com as pesquisas do biomédico gerontólogo Aubrey de Grey, referência nos estudos produzidos sobre medicina anti-aging.

Para os pesquisados, o envelhecimento sugere perdas físicas, mas ganhos intelectuais, tais como a experiência, a sabedoria, conhecimento, ter netos, filhos e conquistas de forma geral. A velhice apareceu como uma opção comportamental, já o envelhecimento físico foi tido como inevitável. No entanto, quando questionados sobre as concepções a respeito de "envelhecer bem", os pesquisados demonstraram acreditar que é possível intervir na forma como se envelhece e que dessa intervenção resultará uma velhice mais ou menos saudável, com mais ou menos limitações. Para a autora, os anseios dos pesquisados convergem com os achados das pesquisas anti-aging, ou seja, acreditam na longevidade com menos declínio físico, menos doença, com maneiras de não se tornar velho.

Dentro da temática "corpo e velhice", o capítulo 4, "O envelhecimento e as mudanças no corpo: novas preocupações e velhas angústias", da pesquisadora 
Beatrice Cavalcante Limoeiro, faz uma reflexão de como os indivíduos percebem as mudanças corporais trazidas pelo envelhecimento. Para tanto, a autora utilizou 1617 questionários aplicados a homens e mulheres da cidade do Rio de Janeiro, de diferentes faixas etárias, a saber: até 39 anos, de 40 a 59 anos e 60 anos ou mais. Além disso, foram utilizadas entrevistas em profundidade realizadas com 18 mulheres cariocas, com mais de 60 anos.

Os pesquisados da faixa de até 39 anos concordaram que o envelhecimento é um processo mais desvantajoso para elas do que para eles e ambos os sexos revelaram medo de se tornarem velhos. Na faixa de 40 a 50 anos, o envelhecimento apareceu como um problema feminino aliado ao desejo de realizar cirurgias plásticas (61\% das entrevistadas). Nenhuma das mulheres dessa faixa etária afirmou que o envelhecimento é pior nos homens. Para Limoeiro (2016), a grande surpresa esteve na faixa dos 60 anos ou mais, na qual ocorreu uma redução acentuada da preocupação feminina com relação à aparência. A questão central para as mulheres do último grupo é saúde, a qualidade de vida e não a estética, como é o caso das demais de outras faixas. Como interpretação dos resultados, a autora ressaltou questões geracionais, contextos históricos e culturais variados.

No quinto capítulo, intitulado "Coroas piriguetes: uma análise sobre envelhecimento, gênero e sexualidade", Larissa Quillinan aborda a discussão em torno do conceito de "piriguete" e de suas características em diferentes universos do território brasileiro. Buscando compreender o duplo estigma que as "coroas piriguetes" vivenciam (ter um comportamento desviante e ser velha), a autora realizou uma pesquisa documental na mídia digital brasileira, a partir de buscadores como "coroas piriguetes" ou "velhas piriguetes". Em blogs e afins, as "coroas piriguetes" são vistas como inadequadas, desviantes e acusadas de "não saberem envelhecer" por manterem relações amorosas e sexuais com homens mais novos e por não se vestirem/comportarem de acordo com o padrão esperado para uma mulher velha. Embora a imagem da "coroa piriguete" seja estigmatizada, de forma geral, sua representação é bastante erotizada nos sites e aparece, com maior frequência, nos pornográficos.

Ainda que apresentem comportamento desviante, Quillinan (2016) não acredita que as piriguetes subvertam totalmente a lógica da dominação masculina. A autora entende que essas mulheres apreendem e reutilizam essa lógica em benefício próprio e, em partes, a forma libertária como usam seus corpos, seus desejos, sua liberdade colocam essas mulheres na condição de desviantes. No entanto, ao mesmo tempo, elas reforçam normas de gênero e dominação já que constroem um corpo hiperfeminilizado como máscara de seu comportamento mais ativo. Além disso, dentro do grupo de "piriguetes", há 
presença de outros estigmas como os de classe e de idade que reforçam outros tipos de dominação simbólica, tal como ocorre com as "coroas piriguetes", o que a autora compreende como o "estigma dentro do estigma".

No capítulo 6, "Internet, sexo e velhice", Veronica Tomsinc revela os resultados de sua pesquisa de campo em uma lan house de Copacabana, na Zona Sul do Rio, bem como das 17 entrevistas em profundidade realizadas com cariocas acima de 50 anos, de ambos os sexos. Com objetivo de compreender como os velhos utilizam a internet em favor de sua sexualidade, foram utilizadas observações na lan house e entrevistas com os profissionais que nela atuam. Os dados da pesquisa de campo in loco revelaram a presença de liberdade e de respeito à privacidade dos usuários, bem como os mecanismos de controle utilizados pelos funcionários que compreendem a configuração espacial e da mobília, o uso de espelhos e o domínio do acesso aos sites acessados. A autora concluiu que a lan house, seja pelo comportamento de seus funcionários ou pela configuração espacial e da mobília, leva em consideração as especificidades do público idoso, mas quanto à questão da sexualidade, reproduz preconceitos em relação à velhice.

Quanto à entrevista com os velhos, não há unanimidade sobre os relacionamentos amorosos virtuais. No entanto, nos discursos produzidos pelos pesquisados, quem se relaciona virtualmente é sempre um terceiro. Em relação ao sexo, apenas dois entrevistados assumiram o interesse em sites pornográficos, porém consideram o sexo transmitido na internet como algo "artificial". Para a autora, a internet pode facilitar a descoberta de novas formas de prazer, mas percebe-se que há uma série de preconceitos relacionados à sexualidade na velhice, seja pelo olhar do outro (no caso, a lan house) ou pelos próprios sujeitos que vivenciam a velhice, que precisam ser vencidos.

O sétimo capítulo, "Corpo, envelhecimento e sociabilidade no bairro de Copacabana", de autoria Mayara Gonzalez de Sá Lobato, refere-se a sua pesquisa sobre a sociabilidade construída por idosos em torno da prática de uma modalidade esportiva no referido bairro. Além das observações e entrevistas com praticantes e não praticantes de vôlei de praia, a pesquisadora utilizou dados da pesquisa conduzida por Mirian Goldenberg com idosos de diferentes bairros cariocas, no que tange o uso de espaços e a prática de atividade física.

Para a autora, o jogo de vôlei na praia de Copacabana favorece a sociabilidade dos velhos à medida que acontece em um clima de descontração e leveza propicio para formação de grupos de amizade. $\mathrm{O}$ corpo não foi considerado um capital para prática do vôlei, bem como não foi detectada preocupação com a exposição do corpo envelhecido na praia. O envelhecimento assumiu um papel dúbio com relação à prática do esporte, uma vez que alguns 
entrevistados apontaram sua falência como fator inconveniente para o jogo. Ao mesmo tempo, a experiência, a inteligibilidade, a sociabilidade e a dedicação foram apontadas como ganhos do envelhecimento para a prática do vôlei de praia. Por último, a autora não notou formas de idadismo entre os praticantes, mesmo que a diferença entre as gerações fossem amplas.

No capítulo 8, intitulado "Jovens há mais tempo", a autora Fernanda Carmagnanis analisou o programa Bonde da Alegria, uma das atividades da Universidade da Terceira Idade da Universidade do Estado do Rio de Janeiro (UnATI/UERJ). O Bonde da Alegria é um produto audiovisual no qual os idosos participam de todo o processo de criação e execução.

Em entrevistas com 11 idosos participantes do programa, a autora pode compreender que abordagem do Bonde da Alegria prioriza a imagem da velhice positivada, na qual os velhos são responsáveis pelo seu processo de envelhecimento. Neste sentido, a autora encontrou a exaltação das novas formas de ser velho, que incluem o indivíduo ativo, com novas possibilidades de aprendizagem, convívio e lazer. Os idosos rejeitam o termo "melhor idade", por reconhecerem os problemas relacionados ao próprio envelhecimento, mas atribuem a si mesmos a definição de "jovens há mais tempo", o que converge com as pesquisas que apontam para a juventude como um valor contemporâneo, independente de um estágio de vida.

No nono e último capítulo do livro "Nós somos uma família", o pesquisador Thiago Barcelos Soliva situa sua pesquisa no âmbito da tradição de estudos sobre sociabilidades gays no Brasil. Soliva (2016) estudou o grupo gay carioca "Turma OK", por se tratar de um dos grupos mais antigos do Brasil, em atividade desde a década de 1960.

Com objetivo de analisar as relações de amizade e os significados atribuídos a elas pelos sócios da "Turma OK", a pesquisa de Soliva (2016) envolveu observação participante, entrevistas em profundidade com seus componentes e análise documental de fotografias e registros de eventos do grupo. Os resultados apontam para construção de vínculos sólidos de amizade entre homens homossexuais pertencentes ao grupo, como aqueles formados pelas relações familiares. Ao longo de sua história, o grupo, com o espaço de sociabilidade, auxiliou seus participantes a reelaborarem sua velhice, tirá-la de uma situação marginal, de um destino social marcado pela solidão e pela falta de cuidados familiares, criando um sistema de proteção no qual se pode encontrar amparo e companheirismo frente aos problemas particulares. Além disso, a "Turma OK" constitui um espaço de sociabilidade para outros velhos, sobretudo mulheres, que frequentam as atividades propostas pelo grupo gay. 
A obra, em seu conjunto, auxilia na compreensão do processo de envelhecimento diferente da perspectiva do declínio - apontada por Simone de Beauvoir, em 1970 - traz um olhar atual e contextualizado para a velhice no cenário nacional e aborda temas pouco explorados por outras obras como a sexualidade, envelhecimento e uso da internet; a gestão das estratégias de identidade e os cabelos brancos; os grupos gays e velhice, dentre outros. Recomendo a leitura de Velho é lindo! aos estudantes e pesquisadores das áreas de Ciências Humanas e Sociais, cujos os estudos tangenciem as temáticas do corpo, sexualidade e envelhecimento. 